\title{
The modeling of the «diaphragm wall» with the anchor without the use of distribution beams
}

\author{
Vladimir Znamenskiy ${ }^{1, *}$, Evgeniy Morozov ${ }^{1}$, Dmitrii Pekin $^{2}$ and Dmitry Chunyuk ${ }^{1}$ \\ ${ }^{1}$ Moscow State University of Civil Engineering, Yaroslavskoe shosse, 26, Moscow, 129337, Russia \\ ${ }^{2}$ LLC «INV-STROY», Moscow, Russia
}

\begin{abstract}
The article describes the features of modeling monolithic trench "diaphragm wall" with ground anchors without the use of distribution beams on the progressive collapse caused by the failure of one of the anchors. In the simulation of the above calculation case, in the flat formulation commonly used in practice, it is assumed that the "diaphragm wall" is a continuous structure in the longitudinal direction, without taking into account the presence of vertical joints formed between the grippers when concreting the fence and the lack of connection between the longitudinal reinforcement of adjacent reinforcement spatial frameworks. The performed calculations show that the failure to take into account these circumstances leads to a significant reassessment of the ability of the "diaphragm wall" to redistribute the load from the broken anchor to the neighboring anchor and can lead to an incorrect assessment of the results of the calculation for a progressive collapse. The need to take into account the reduction of structural rigidity of the "diaphragm wall" due to the formation of cracks in two directions is also shown.
\end{abstract}

\section{Introduction}

The practice of calculating the structure of the fence of ditch in various software complexes shows that at modeling of their work not count a number of an important features, underestimation of which can lead not only to destruction of separate elements of the structure of the fence of ditch, but also to cause the phenomenon of progressive collapse (loss of stability of its separate sites or system as a whole).

Such a calculated situation was considered in the design of the fence of ditch in Moscow. The structure of the fence of ditch was represented by a monolithic reinforcedconcrete "diaphragm wall" of the trench type with a thickness of $600 \mathrm{~mm}$, a depth of 21.5 $\mathrm{m}$, with the use of concrete class for uniaxial compression strength B40 and reinforcing the spatial frames from A500C class rods.

The lower end of the "diaphragm wall" was inserted into the watertight layer at 3.85$5.95 \mathrm{~m}$, which allowed us to consider it as an slurry trench of the perfect type. On the top of the "diaphragm wall" was provided a device of the monolithic reinforced-concrete bundling beam section $600 \times 700(\mathrm{~h}) \mathrm{mm}$.

\footnotetext{
* Corresponding author: geosts@yandex.ru
} 
The stability of the "diaphragm wall" during the development of the ditch was ensured by its penetration into the ground below the bottom of the ditch at $5.95 \mathrm{~m}$ and the device of 3 tiers of temporary pre-stressed injection ground anchorage installed in $1.5 \mathrm{~m}$ steps.

The "diaphragm wall" was arranged on the site, in the geological structure of which modern soil formations, modern man-made deposits, Upper Quaternary cover deposits, Middle Quaternary fluvio-glacial deposits of the Moscow horizon, medium Quaternary sea deposits of the Moscow and the Don horizon took part.

Modern soil formations were represented by a soil-plant layer with a thickness of up to $0.2 \mathrm{~m}$.

Modern technogenic deposits (EGE-1), opened from the surface to a depth of 0.3-3.2 m, were represented by bulk soils: clay loam low-plasticity with inclusions of construction debris up to $5 \%$ unclimbed.

The Upper Quaternary cover deposits were represented by loamy, layered, semi-solid loams with interlayers of hard and turgid (EGE-2) loam, 0.4-3.2 m thick.

Mid-Quaternary fluvioglacial deposits of the Moscow horizon were represented by loams and sands:

- silty sand, middle density, middle degree of water saturation and water saturated, with interlayers of soft-plastic loam and sand-clay plastic, with rare inclusions of gravel, heavy clayey, 0.5-3.7 $\mathrm{m}$ in thickness (EGE-3);

- sandy loam, soft-plastic, with inclusions up to $10 \%$ gravel, fine gravel (EGE-4), with a thickness of 0.6-5.2 m;

- sandy loam, low-plasticity, with interlayers of loam semi-solid, with inclusions up to $10 \%$ gravel, fine gravel (EGE-5), with a thickness of 0.4-6.5 m.

Mid-Quaternary moraine deposits of the Moscow horizon were represented by loams and sands:

- sandy loam, semi- hard, with interlayers of loam hard, with interbeds of semi-solid clay, with inclusions of up to $10 \%$ of gravel, fine gravel (EGE-6b), capacity of 0.5-9.5 m;

- gravelly sand, dense, water saturated, with interbeds of dusty sand with inclusions of pebbles (EGE-7b), with a thickness of 0.3-6.0 m.

Mid-Quaternary moraine deposits of the Don horizon were represented by loam hard, with inclusions of up to $30 \%$ gravel, carbonates fine gravel, lime (EGE-8), with a thickness of 3.5-18.6 m.

The hydrogeological conditions of the site were characterized by the presence of three aquifers - Intermoraine and Jurassic. The Intermorainal aquifer was opened at a depth of 5.5-13.9 $\mathrm{m}$, the Jurassic aquifer at a depth of 28.0-31.7 $\mathrm{m}$.

The design scheme of the "diaphragm wall" at the geological section of the construction site is shown in Fig. 1. 


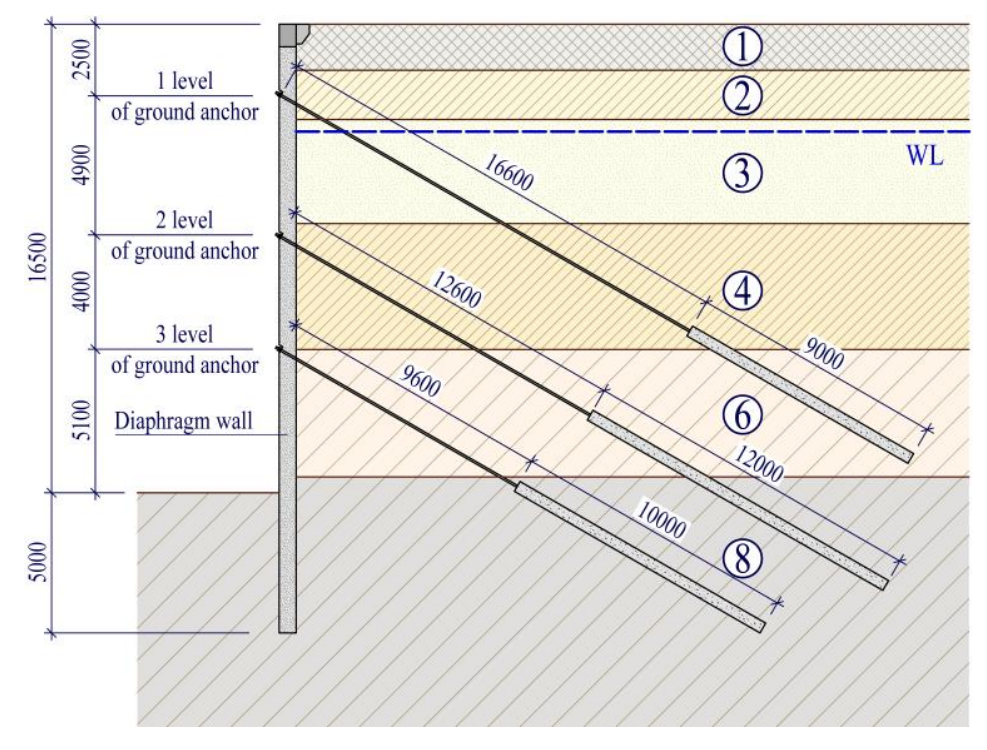

Fig. 1. Calculation scheme of the fence of ditch

\section{Methods}

To determine the additional forces that arise in the traction of ground anchors and the construction of "diaphragm wall" with the exclusion of one anchor from the work, the simulation of the design scheme in the software Midas GTS NX 2018 was performed. The dimensions of the design model $(90 \times 60 \mathrm{~m})$ were adopted in such a way that the boundary conditions did not influence the results of the calculation. The construction of the "diaphragm wall" was made in the form of plate elements, rod finite elements were used to model anchors. The width of the design model corresponded to the length of the block of concreting $6 \mathrm{~m}$. Thus, the change of the stress - strain state in the system "anchors concreting section" of the "diaphragm wall" - the surrounding soil mass" was considered taking into account its spatial work and the main stages of excavation of the ditch.

After the completion of the last stage - the development of the soil before the marking of the bottom of the ditch, the situation with the failure of one anchor of the last row was considered as the most unfavorable during the development of the ditch. Accordingly, three calculated situations were considered and the parameters of the stress - strain state of the "anchors - concreting section of the "diaphragm wall" - the surrounding soil mass", as well as the coefficient of stability were determined.

According to the results of the calculation, it was found that the force values when the anchor is out of order, arising in the structures of the ditch fence (in the ground anchors and the "diaphragm wall" body) do not exceed their limit values and the phenomenon of progressive destruction does not occur

It should be noted that when modeling the fragment of "diaphragm wall" was considered as a single monolith with constant properties, i.e. did not take into account the presence of the concreting joint in the junction of concreting section of the "diaphragm wall" was not taken into account, the resistance in which is significantly lower than the resistance to the shift of the reinforced concrete section outside the concreting joint, and the lack of a connection between the horizontal longitudinal working reinforcement of adjacent 
reinforcing space frames, leading to a noticeable decrease in the bending stiffness of the structure.

In addition, was not taken the decrease in the initial modulus of elasticity of concrete into account due to the formation and opening of cracks and not elastic work of concrete in the compressed zone, resulting in a decrease in the bending stiffness and distribution capacity of the fence of structure.

Against the backdrop of considerable efforts in the structure of the "diaphragm wall" arising in the vertical and horizontal directions due to the lack of distribution beams and the escape from the work of one anchor, special concernment was caused by a lack of horizontal reinforcement in the construction of the spatial frameworks and its absence in the middle of the concreting section.

Thus, the justification of the calculation for the strength and stability of the "diaphragm wall" when one of the anchors is failure was considered insufficient, which required new calculations taking into account the shortcomings described.

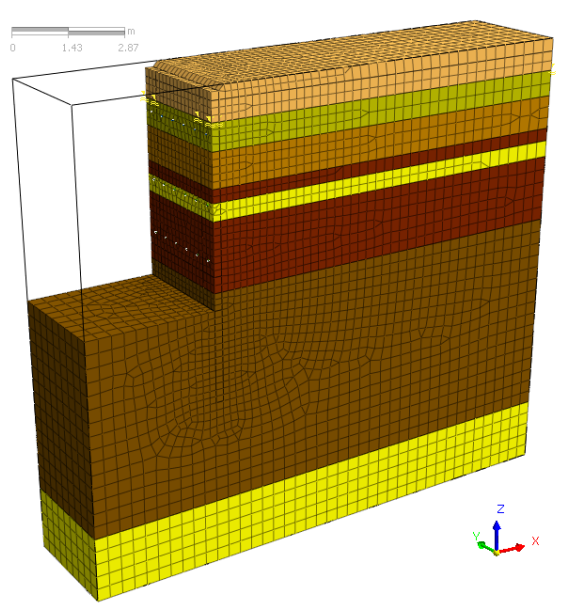

a) General view.

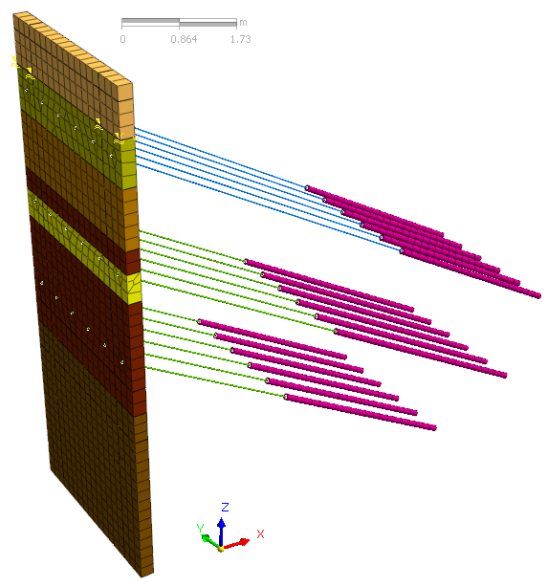

b) A fragment of a "diaphragm wall" with ground anchors.

Fig. 2. Calculating scheme.

When simulating an alternative calculating scheme in the Midas GTS NX 2018 software, the width of the design area was increased to $12 \mathrm{~m}$ and contained a 6-meter block of concreting and adjacent to it on both sides of half of the adjacent section, for the structure of the "diaphragm wall" were used three-dimensional finite elements, the concreting sections are separated by contact interface elements, allowing the blocks of concreting to move relative to each other. Also, the bending stiffness of the "diaphragm wall" was lowered by reducing the initial modulus of elasticity of concrete by $60 \%$.

\section{Results}

According to the results of the analysis of the calculation it was found that the forces arising in the tendon, when leaving the work of one of them increased by $20-25 \%$ (depending on the location of the excluded anchor) compared to the values obtained in the previous calculation. It should be note that the increased effort in the tendon caused by the exception of the work of the ground anchor did not exceed their bearing capacity. The distribution of forces between the anchors have a major impact by the "cutting" of the 
"diaphragm wall" structure on the concreting blocks, since in this case the forces from the excluded anchor from were distributed among themselves between the captures, and the anchors of the neighboring blocks took a small part within 10-15\%. Also founded that the most unfavorable combination of loads was achieve by excluding the anchor from the extreme row in the lower tier.

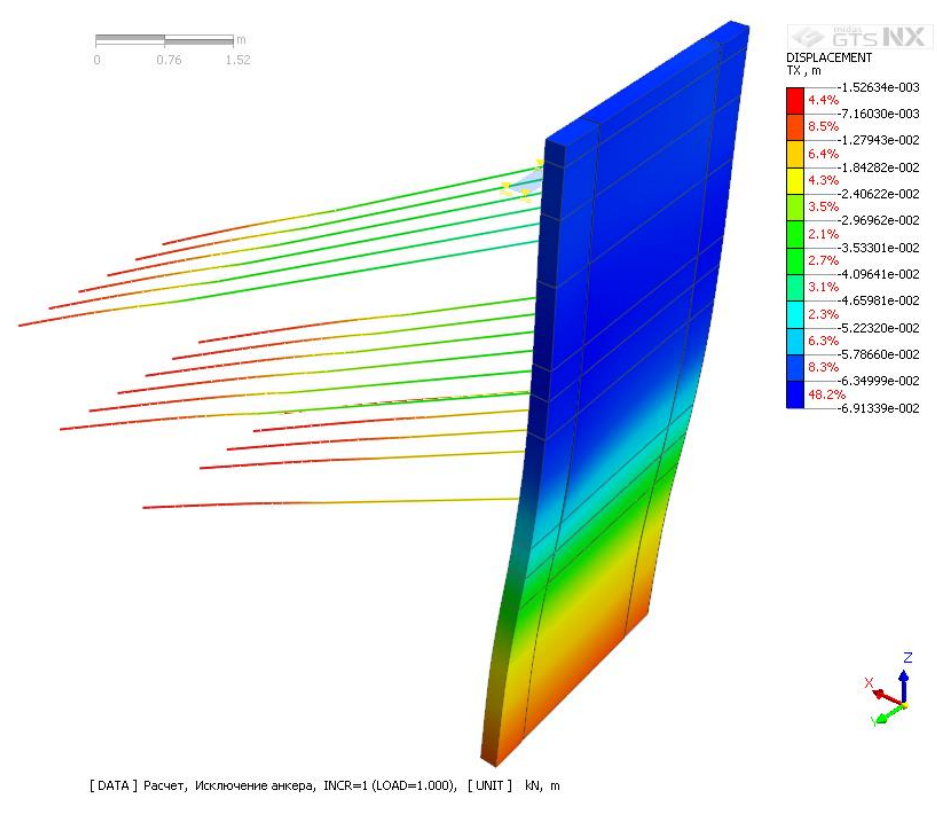

Fig. 3. The displacement fields of "diaphragm wall", when the anchor is excepted.

Due to the fact that the calculation model executed in the Midas GTS NX 2018 software does not take into account the reinforcement parameters and the gap between two reinforcing space frames installed in one concreting section ( 2 frames by 3 meter are installed in section by length 6 meter), for the estimate influence of the parameters of reinforcement and the reduction of the structure bending stiffness of the ditch fence on its distribution ability, a model was prepared in the software SCAD 21.1, taking into account the calibration of the stress-strain state of structure "diaphragm wall" received, based on the results of the corrected calculation in the Midas GTS NX 2018 software. The results of the calculating by software SCAD 21.1 defined that when is excepted the negative anchor in the third tier, then taken reinforcement of the "diaphragm wall" in horizontal direction don't satisfy to demand Ultimate Limit State (by strength) by $27 \%$. In addition, taking into account the lack of connection between the horizontal longitudinal reinforcement of the neighboring reinforcing space frames in one block of concreting is most chance to opening a vertical crack along the junction zone of adjacent reinforcing frames, which will lead to the formation of an additional "uncontrolled" weld. In this case, the distribution of forces will be carried out between the anchors within a three-meter section of concreting (from the concreting joint to the crack). It should also be noted that, due to the lack of waterstops along the junction zone of spatial frames within one section of concreting, the resulting force crack can cause leakage in the watertight structure of the "diaphragm wall". 


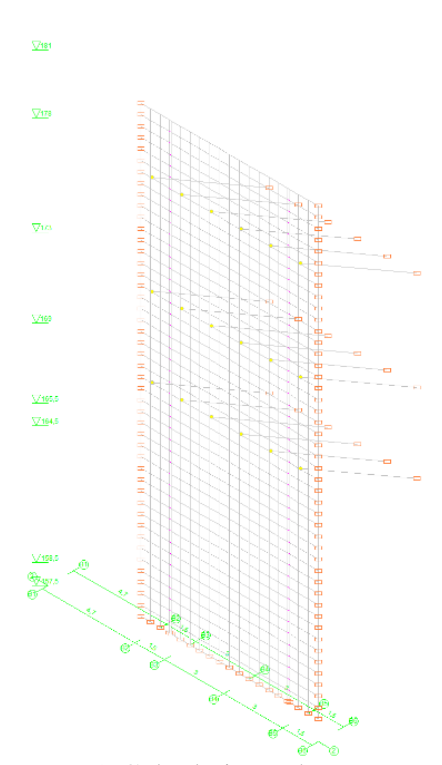

a) Calculating scheme

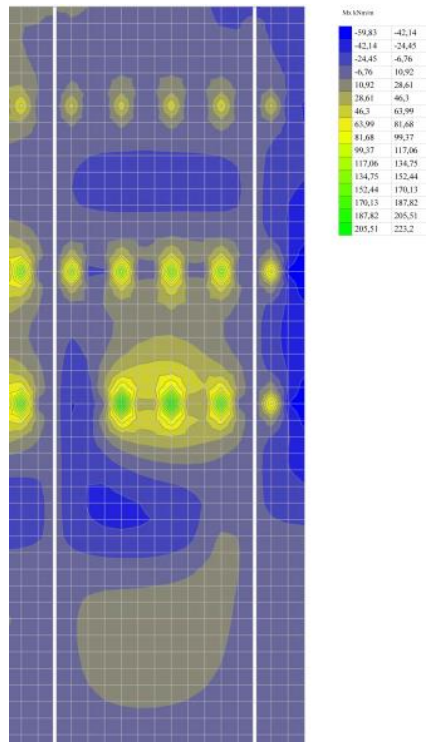

b) The bending moments fields in horizontal direction

Fig. 4 The results of calculating of structure «diaphragm wall» in SCAD 21.1 software.

In connection with the above, in the software Midas GTS NX 2018, a repeated simulation of the calculated situation with the separation of the "diaphragm wall" into concreting blocks with a length of 3 meter was performed. As a result of the calculation data were obtained, the analysis of which showed that the excepted from the work of one of the ground anchors, forces in the neighboring anchors reached their bearing capacity, which indicated the Ultimate Limit State of the work of the structure and could lead to the phenomenon of progressive collapse.

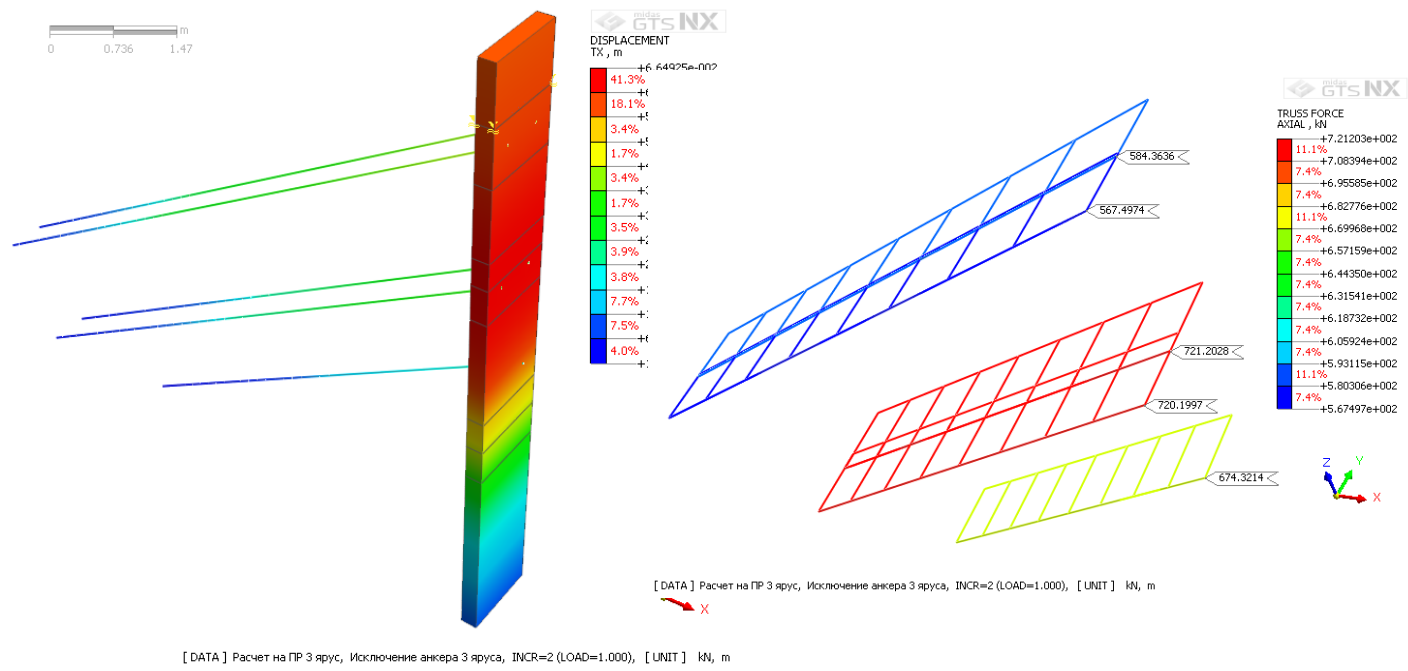

a) The displacement fields of "diaphragm wall"

b) Axial force diagram in the tendon of ground anchors

Fig. 5. The results of calculating of structure "diaphragm wall", when the anchor is excepted 


\section{Conclusions}

Based on the results of the calculations, it is established that the values of additional forces caused by the failure of one of the anchors depend to a large extent on the location of the excavated soil anchor, the rigidity of body of the "diaphragm wall", and the length of the block of concreting.

When developing a scheme for calculating the "diaphragm wall" for progressive collapse, which simulates the exit from the work of a one ground anchor, it is necessary to take into account the flexibility of its structure in the zone of vertical concreting joints separating the blocks of concreting and the presence of cracks reducing the bending rigidity of the "diaphragm wall "and, as a result, its distributive capacity.

When calculating the monolithic reinforced concrete "diaphragm wall" without the use of horizontal distribution beams, the spatial nature of the work of the structure of ditch fence should be taken into account, since it works bending in two directions, and the values of forces (the bending moments) hightly increase when one of the anchors fails, which must be taken into account when selecting of the reinforcement.

This work was financially supported by Ministry of Science and Higher Education of the Russian Federation (\#NSh-3492.2018.8).

\section{References}

1. V.A. Ilichev, V.V. Znamenskiy, E.B. Morozov, D.Yu. Chunyuk, Sb. trudov nauchn. texn. konf. "Aktualnye voprosy geotexniki pri reshenii slozhnyx zadach novogo stroitelstva i rekonstrukcii, Spb., Opyt ustrojstva kotlovanov v gorode Mockve, 33, (2010)

2. V.V. Znamenskiy, D.Yu. Chunyuk, E.B. Morozov, Zhilishhnoe stroitelstvo, Ustrojstvo ograzhdayushhix sistem kotlovanov v stesnenny`x gorodskix usloviyax, 9, 60 (2012)

3. D.A. Pekin, Arxitektura $i$ stroitelstvo Rossii, Plitnaya stalezhelezobetonnaya konstrukciya, 8, 20 (2009)

4. N.N. Trekin, D.A. Pekin, Promyshlennoe $i$ grazhdanskoe stroitelstvo, Skrytye metallicheskie kapiteli bezbalochnyh monolitnyh perekrytiy, 7, 17 (2014)

5. K.J. Willam, E.D. Warnke, Constitutive Model for the Triaxial Behavior of Concrete, Proceedings, International Associations for Bridge and Structural Engineering, ISMES, Bergamo, Italy, 19 (1975) 